\title{
Culling of APCs by inflammatory cell death pathways restricts TIM3 and PD-1 expression and promotes the survival of primed CD8 T cells
}

\author{
Rajen Patel ${ }^{1}$, Kwangsin Kim ${ }^{1}$, Bojan Shutinoski ${ }^{1}$, Kristina Wachholz ${ }^{1,2}$, Lakshmi Krishnan ${ }^{1,2}$ and Subash Sad ${ }^{\star 1}$ \\ We evaluated the impact of premature cell death of antigen-presenting cells (APCs) by Caspase-1- and RipK3-signaling pathways \\ on $\mathrm{CDB}^{+}$T-cell priming during infection of mice with Salmonella typhimurium (ST). Our results indicate that Caspase1 and RipK3 \\ synergize to rapidly eliminate infected APCs, which does not influence the initial activation of $\mathrm{CD}^{+} \mathrm{T}^{\mathrm{T}}$ cells. However, the \\ maintenance of primed $\mathrm{CD}^{+} \mathrm{T}$ cells was greatly compromised when both these pathways were disabled. Caspase-1- and \\ RipK3-signaling did not influence NF-кB signaling in APCs, but synergized to promote processing of IL-1 and IL-18. Combined \\ deficiency of Caspase1 and RipK3 resulted in compromised innate immunity and accelerated host fatality due to poor processing \\ of IL-18. In contrast, synergism in cell death by Caspase-1- and RipK3 resulted in restriction of PD-1 and TIM3 expression on \\ primed $\mathrm{CD}^{+} \mathrm{T}$ cells, which promoted the survival of activated $\mathrm{CD} 8^{+} \mathrm{T}$ cells.
}

Cell Death and Differentiation (2017) 24, 1900-1911; doi:10.1038/cdd.2017.112; published online 7 July 2017

Dendritic cells (DCs) and macrophages utilize pathogen recognition receptors (PRRs) to detect pathogen-associated molecular patterns (PAMPS). This culminates in the expression of inflammatory cytokines, which promotes rapid pathogen-control. ${ }^{1}$ DCs induce antigen-presentation, which results in early priming of $T$ cells that peaks by day 7 postinfection. $^{2,3}$ Co-stimulatory (CD28) and inhibitory (PD-1) receptor engagement on primed $T$ cells during their differentiation has been shown to have opposite impact on the fate and function of primed $\mathrm{CD}^{+} \mathrm{T}$ cells. ${ }^{4,5}$

Salmonella serovars cause enterocolitis, sepsis, typhoid, inflammatory bowel disease and cancer. ${ }^{6-8}$ Infection of mice with Salmonella enterica serovar Typhimurium (ST) results in early host fatality, which is partly attributed to a mutation in the natural resistance-associated macrophage protein-1 (Nramp1) gene, which encodes a key ion transporter in the phagosome. ${ }^{9}$ While the engagement of PAMPs by PPRs results in the activation of innate immune response, the release of danger-associated molecular patterns (DAMPs) from cells undergoing inflammatory cell death results in potent activation of innate immune response. ${ }^{10-13}$ Inflammatory cell death is often pervasive during virulent infections. ${ }^{11,14,15}$ Pyroptosis is the result of inflammasome signaling that results in auto-activation of Caspase-1, which then processes pro-IL-1 $\beta$ and pro-IL-18 into their active forms. ${ }^{11}$ Necroptosis is induced by phosphorylation of the receptor interacting protein kinase 1 (RipK1) following TLR- or cytokine receptor signaling, ${ }^{16-18}$ leading to interaction of RipK1 with Caspase-8 and RipK3. Both pyroptosis and necroptosis results in membrane rupture, release of intracellular DAMPs and the induction of inflammation. ${ }^{10,13}$
In this report, we evaluated whether the cell death of antigen-presenting cells (APCs) by Caspase-1 and RipK3 signaling has any impact on $\mathrm{CD}^{+}$T-cell priming during infection with ST. Our results indicate that Caspase-1-and RipK3-signaling synergize to promote the processing of IL-1/18, which resulted in efficient innate immune response and pathogen control. Furthermore, synergism in the inflammatory cell death of APCs mediated by Caspase-1-and RipK3-signaling was necessary to restrict the inhibitory receptor (PD-1, TIM3) expression in primed $\mathrm{CD}^{+} \mathrm{T}$ cells to ensure efficient differentiation and survival of primed $C D 8^{+}$ T cells.

\section{Results}

Combined deficiency of caspase-1,11 and RipK3 signaling compromises cell death of infected APCs, which limits CD8 $^{+}$T-cell priming. We generated mice that are double-deficient in Caspase-1,11 and RipK3 in order to block the cell death mediated by these pathways and evaluate the impact on antigen-presentation and $\mathrm{CD}^{+} \mathrm{T}$-cell priming. Flow cytometric analysis revealed that WT, Caspase-1, 11-, RipK3- and Caspase-1,11-RipK3-double-deficient mice have similar numbers of various immune cell populations at steady state (Supplementary Figure S1). We infected DCs or macrophages with ST-OVA in vitro and measured cell death at $24 \mathrm{~h}$ post-infection (Figures $1 \mathrm{a}$ and $\mathrm{b}$ ). A graded impact was observed in cell death of DCs and macrophages following infection with ST with the wild-type cells undergoing maximal cell death in comparison to the double-deficient APCs that display no cell death. Infected DCs from Caspase-

${ }^{1}$ Department of Biochemistry, Microbiology and Immunology, Faculty of Medicine, University of Ottawa, Ottawa, Ontario, Canada and ${ }^{2}$ National Research Council of Canada, Ottawa, Ontario, Canada

${ }^{*}$ Corresponding author: S Sad, Department of Biochemistry, Microbiology and Immunology, Faculty of Medicine, University of Ottawa, 451 Smyth Road, Ottawa, ON K1H 8M5, Canada. Tel: 6135625800 x8336; Fax: 613562 5452; E-mail: subash.sad@uottawa.ca

Received 12.12.16; revised 17.5.17; accepted 06.6.17; Edited by L Zitvogel; published online 07.7.17 
a

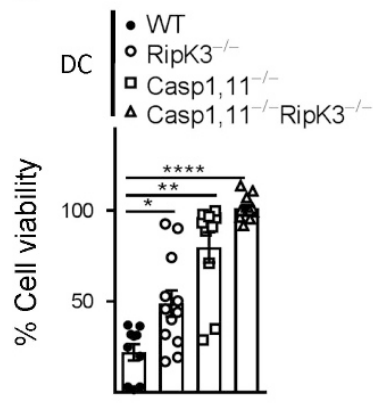

b M $\phi \mid \begin{array}{ll}\bullet & \text { WT } \\ \circ & \text { RipK3 } \\ \text { a } & \text { Casp1 } 1,11^{-/-} \\ \Delta & \text { Casp1 } 1,11^{-/-} \text {RipK3 }^{-/-}\end{array}$

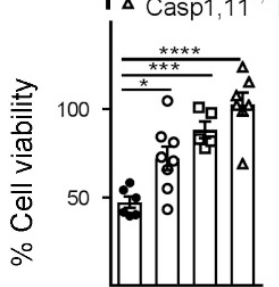

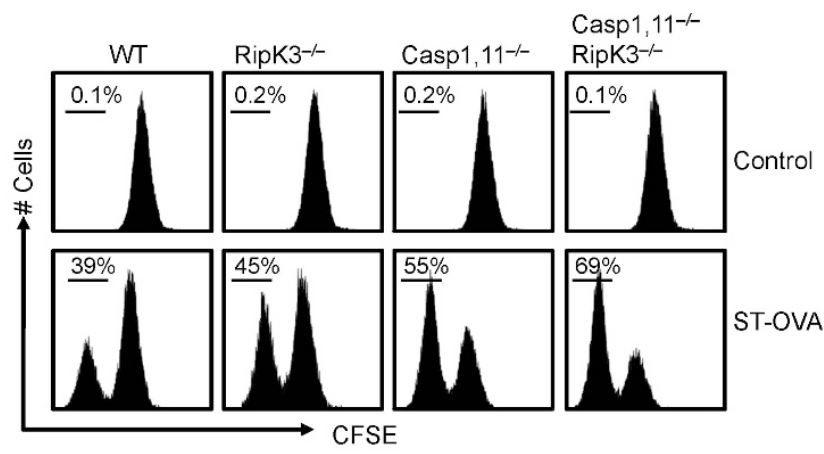

d

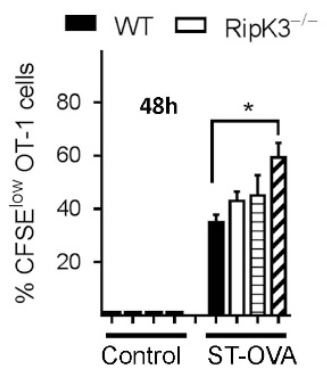

e

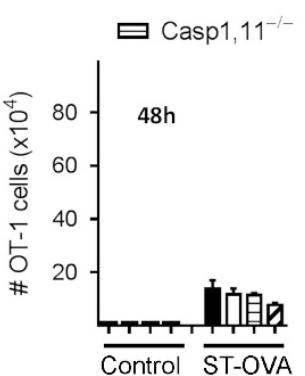

$\mathbf{f}$

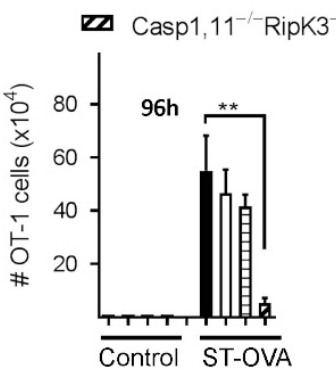

Figure 1 Synergism of Caspase-1,11 and RipK3 signaling promotes cell death of APCs and expansion of primed CD8 ${ }^{+}$T cells in vitro. DCs (a) and macrophages (b) from

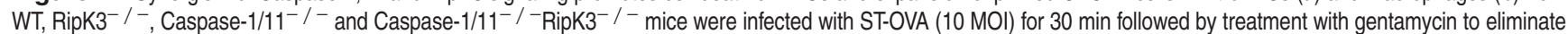
extracellular bacteria. At $24 \mathrm{~h}$ post-infection, cell viability was evaluated by neutral red assay. (c-f) Control and infected DCs from the various groups of mice were infected with STOVA as mentioned above. Cells were incubated with CFSE-labeled OT-1 transgenic $\left(\mathrm{OVA}_{257-264}\right.$ specific) CD8 ${ }^{+} \mathrm{T}$ cells. After $48 \mathrm{~h}$ (c-e) and $96 \mathrm{~h}$ (f), CFSE-dilution of proliferating OT- 1 CD $8^{+} T$ cells and numbers of OT- 1 CD $8^{+} T$ cells were evaluated by flow cytometry. The Data are shown as mean \pm SEM and is representative of $2-3$ separate experiments. Statistical analysis was performed by unpaired student $t$-test $\left({ }^{*} P<0.05,{ }^{* *} P<0.01,{ }^{* * * *} P<0.0001\right)$

1,11-RipK3-double-deficient mice upon co-culture with CFSE-labeled OT-1 TCR transgenic $\mathrm{CD}^{+} \mathrm{T}$ cells in vitro induced slightly better proliferation of OT-1 cells when measured at $48 \mathrm{~h}$ (Figures $1 \mathrm{c}-\mathrm{e}$ ). However, OT-1 cells that had been stimulated by Caspase-1,11-RipK3-double-deficient DCs underwent a massive attrition subsequently, whereas OT-1 cells stimulated by WT, Caspase-1,11- or RipK3-deficient DCs continued to increase in number (Figure 1f).

We next infected mice with ST-OVA $\left(10^{3}\right.$, iv) to evaluate the impact of Caspase-1,11 and RipK3 signalling on the death of DCs and priming of CD8 ${ }^{+} \mathrm{T}$ cells in vivo. The number of DCs in infected Caspase-1,11-RipK3-double-deficient mice was slightly greater than all the other three groups of mice at $24 \mathrm{~h}$ post-infection (Supplementary Figure S2a, b). To avoid the complexity of changes in DCs numbers due to migration of naive DCs from bone marrow to spleens of infected cells, we transferred naive DCs from WT, RipK3-, Caspase-1,11- and Caspase-1,11-RipK3-double-deficient mice (all CD45.2 ${ }^{+}$) into B6.SJL mice $\left(C D 45.1^{+}\right)$, and evaluated the relative numbers of donor $\left(C D 45.2^{+}\right)$DCs in recipient $\left(C D 45.1^{+}\right)$mice at 24 h postinfection with ST-OVA (Figure 2a). The numbers of Caspase1,11-RipK3-double-deficient DCs were highest in comparison to WT, RipK3- or Caspase-1,11- deficient DCs (Figures $2 \mathrm{~b}$ and c). These results suggest that both Caspase-1,11- and RipK3signalling induce cell death of infected DCs and both the pathways need to be disabled in order to prevent cell death completely. To measure antigen-presentation in vivo, a different experimental model was used wherein CFSE- labeled OT- 1 cells (CD45. $1^{+}$CD45. $\left.2^{+}\right)$were adoptively transferred into WT, RipK3-, Caspase-1,11- and Caspase-1,11RipK3-double-deficient mice (iv) one day before infection with ST-OVA (Figure 2d). All recipient mice were CD45.2 ${ }^{+}$. Proliferation and expansion in the numbers of transferred OT- 1 cells was evaluated at $72 \mathrm{~h}$ post-infection. Although there was a trend towards increased proliferation of OT-1 cells in infected Caspase-,11-RipK3-double deficient mice, this did not achieve significance (Figures $2 e$ and f). Interestingly, the numbers of primed OT-1 cells were drastically reduced in infected Caspase-1,11-RipK3-double deficient mice (Figure $2 \mathrm{~g}$ ), suggesting the double-deficiency of Caspase1,11 and RipK3 may compromise the survival of primed CD8 ${ }^{+}$ $\mathrm{T}$ cells. The bacterial burden was slightly higher in the spleens of infected Caspase-1,11-RipK3-double-deficient mice (Figure 2h). Taken together, these results indicate that Caspase-1,11 and RipK3 signalling synergize to induce cell death of APCs, which causes an impairment in the proliferation/survival of primed $\mathrm{CD}^{+} \mathrm{T}$ cells.

The processing of IL-1 but not MAPK or NF-kB signaling is compromised by combined deficiency of Caspase- 1 , 11 and RipK3 signaling. Since we were interested in evaluating the impact on antigen-presentation and $\mathrm{CD}^{+}$ T-cell priming, we evaluated the impact of Caspase-1/11 and RipK3 signaling in DCs. We infected DCs with ST-OVA and measured the phosphorylation of p38 MAPK and NF-kB. Phosphorylation of $\mathrm{p} 38 \mathrm{MAPK}$ and NF-KB was induced in DCs upon infection with ST-OVA, but there was no impact of 


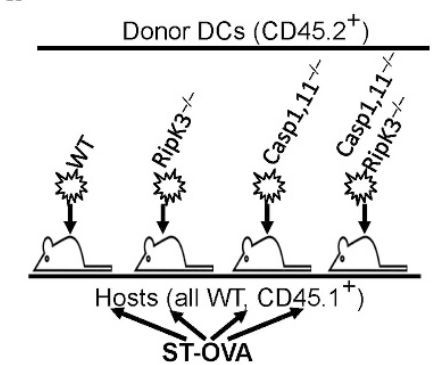

d

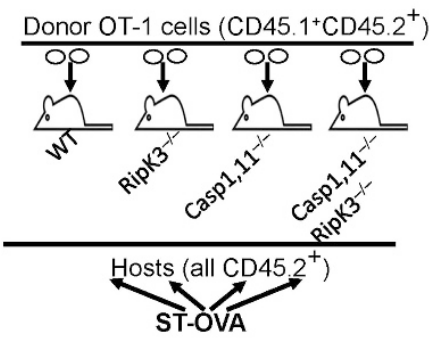

b

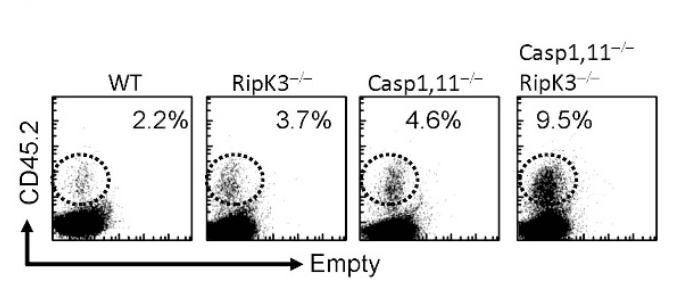

$\mathbf{f}$

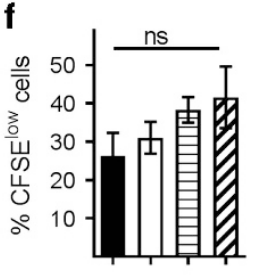

e

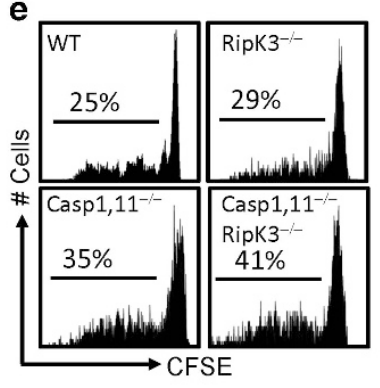

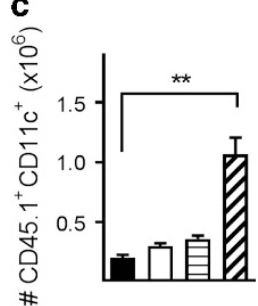

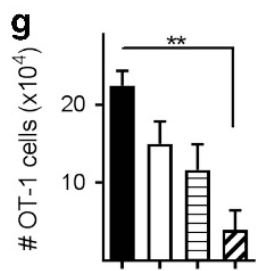

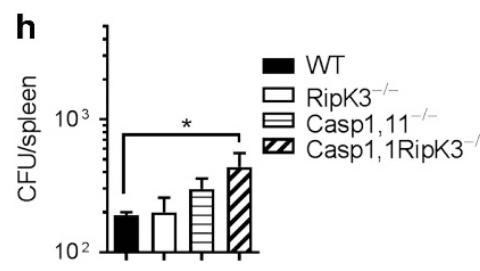

Figure 2 Inflammatory cell death of APCs promotes better CD8 ${ }^{+}$T-cell expansion in vivo. (a-c) DCs from WT, RipK3-, Caspase-1,11- and Caspase-1,11-RipK3-deficient mice (all CD45. $\left.2^{+}\right)$were injected $\left(2 \times 10^{7}\right.$, i.v.) into B6.SJL $\left(C D 45.1^{+}\right)$recipient mice. Recipient mice were infected with ST-OVA $\left(10^{5}\right.$, i.v.) the same day (a) and the numbers of transferred DCs in the spleens of recipient hosts evaluated by flow cytometry $(\mathbf{b}, \mathbf{c})$ at $24 \mathrm{~h}$ post-infection. (d-h) Purified CFSE-labeled OT-1 CD8 ${ }^{+}$T cells $\left(\mathrm{CD} 45.1^{+} \mathrm{CD} 45.2^{+}\right)$were injected (i.v., $10^{5}$ per mouse) into WT, RipK3-, Caspase-1,11- and Caspase-1,11-RipK3-deficient mice (all CD45.2 ${ }^{+}$) followed by infection of recipient mice with ST-OVA the next day (d). At $72 \mathrm{~h}$ post-infection, OT-1 cells (CD45. $\left.1^{+} \mathrm{CD} 45.2^{+}\right)$were tracked in the spleens of infected recipient mice (CD45.1-CD45.2 $)$, and the reduction of CFSE expression in OT-1 cells (e, f) and numbers of transferred OT-1 cells $(\mathbf{g})$ were evaluated by flow cytometry. (h) Bacterial burden was evaluated in the spleens of infected mice at $72 \mathrm{~h}$ postinfection. The data are shown as mean \pm SEM and is representative of $2-3$ separate experiments. Statistical significance was determined by unpaired student $t$-test $\left({ }^{* *} P<0.01\right)$

Caspase-1,11- or RipK3- signaling (Figure 3a). There was no impact on the expression of RipK1 or NLRP3/NLRC4 or proIL-1 $\beta /$ IL-18 (Figure 3b). We also measured cytokine expression by DCs following infection with ST-OVA. Cells were infected with a reduced dose of ST-OVA to avoid cell-death. This was done to ensure that cytokine expression was not compromised by premature death of infected cells. IL-1a, which is mainly released by dying cells ${ }^{19}$ was significantly reduced in Caspase-1,11- and RipK3- deficient cells. Caspase-1,11-RipK3-double-deficient DCs had the greatest reduction in IL-1a secretion (Figure $3 \mathrm{c}$ ). Similar results were noted when the expression of $\mathrm{IL}-1 \beta$ was measured. In contrast, the expression of other inflammatory and antiinflammatory cytokines was not impacted by Caspase-1,11 or RipK3 deficiencies (Figure 3c). We also measured the impact of Caspase-1/11 and RipK3 signaling in macrophages, which are not as efficient as DCs in mediating antigen-presentation. The impact of Caspase-1/11 and RipK3 in macrophages was similar to that in DCs (Supplementary Figure S3a-d). Caspase-1,11 or RipK3 did not have any impact on NF-kB or p38 MAPK signaling in macrophages.

Caspase-8 plays a promiscuous role in comparison to Caspase-1 in promoting the processing of IL-1. In addition to Caspase-1, Caspase-8 has been shown to cleave proIL-1 $\beta$ upon TLR stimulation. ${ }^{20}$ We thus utilized Caspase-8 inhibitor (ZIETD) and Caspase-1 inhibitor (YVAD) to evaluate the relative contribution of these two Caspases in promoting the processing of IL-1. Inhibition of Caspase-1 (with YVAD) resulted in potent reduction of both $\mathrm{IL}-1 \alpha$ and $\mathrm{IL}-1 \beta$ levels in WT and RipK3-deficient DCs, but not in Caspase-1,11- or Caspase-1,11-RipK3-deficient DCs as expected (Figures 4ac). Interestingly, inhibition of Caspase-8 (with zIETD) resulted in the reduction of $\mathrm{IL}-1 \beta$ levels in DCs from all the four groups of mice, with the most impact observed in Caspase-1,11-RipK3double-deficient DCs (Figure 4d). The magnitude of impact was greater with Caspase-1 in comparison to Caspase-8, on IL-1 $\beta$ processing, as revealed by the inhibition of these two Caspases with their respective inhibitors (Figure 4d). However, Caspase-1 impacted IL-1 $\beta$ secretion only in WT and RipK3deficient DCs, whereas Caspase- 8 impacted IL- $1 \beta$ processing in DCs from all the four groups of mice (Figure $4 d$ ). The greatest impact of Caspase-8 activity was noticeable in the Caspase-1,11-RipK3-double-deficient DCs.

The activation of NF-kB and Caspase- 1 has been shown to be influenced by cellular inhibitors of apoptosis proteins (clAPs). ${ }^{21-23}$ We tested whether clAPs influenced the processing of IL-1 following infection with ST. DCs were infected with ST and treated with the SMAC mimetic, Birinapant (BIR), which causes rapid degradation of clAPs. Co-treatment of infected DCs with the SMAC mimetic resulted in increased processing of IL-1 (Figures $4 \mathrm{e}$ and $\mathrm{f}$ ), indicating that clAPs regulate IL-1 processing during infection with ST. Importantly, clAPs regulated both Caspase-1,11- and RipK3-dependent 
a

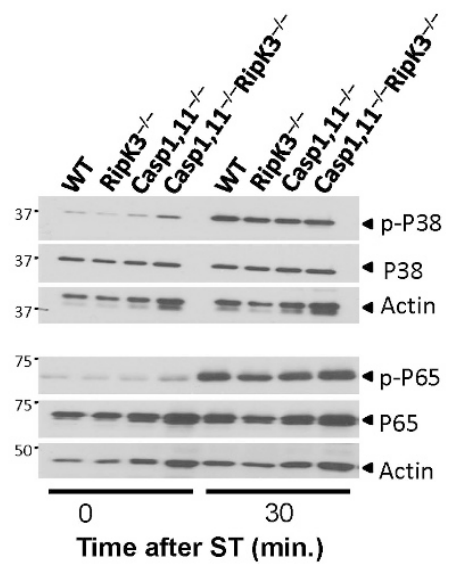

C
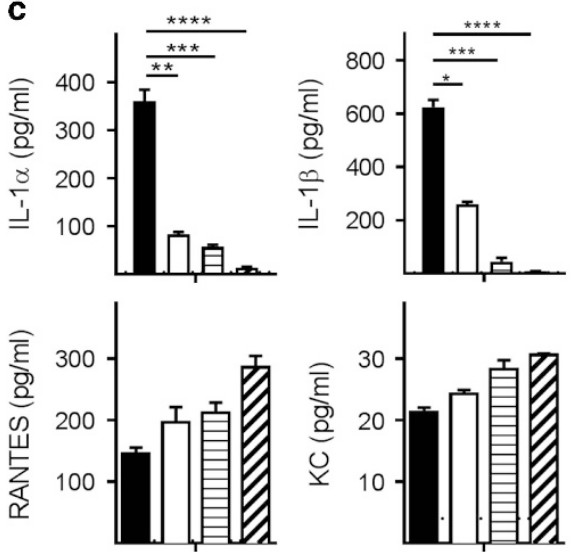
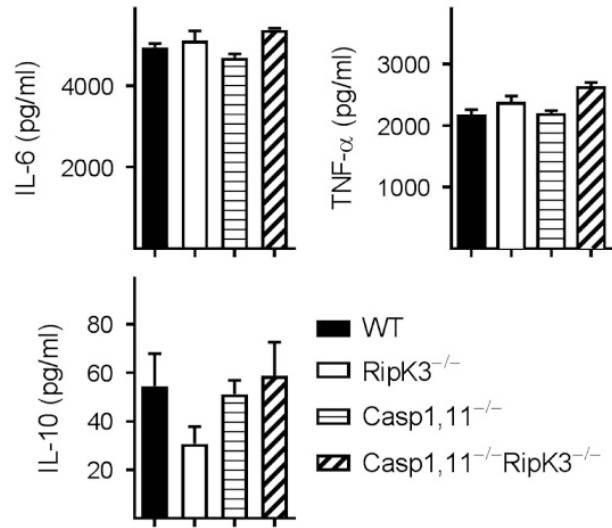

WT

RipK3

Casp1,11

Casp $1,11^{-/-}$RipK3 $^{-1}$

Figure 3 Inflammatory cell death of APCs does not impact NF-kB and MAPK signaling. (a,b) DCs were infected with ST-OVA (10 MOI) and western blot analysis was

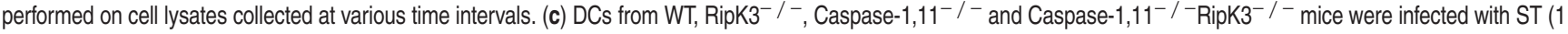
$\mathrm{MOI}$ ) for $30 \mathrm{~min}$ followed by treatment with gentamycin to eliminate extracellular bacteria. Expression of cytokines and chemokines was measured in the supernatants collected at $24 \mathrm{~h}$ supernatants post-infection. The data are shown as mean \pm SEM and is representative of $2-3$ separate experiments. Statistical significance was determined by unpaired student $t$-test $\left({ }^{\star} P<0.05,{ }^{* \star} P<0.01,{ }^{* \star *} P<0.001,{ }^{* \star *} P<0.0001\right)$

pathways, and the impact was greatest in Caspase-1,11RipK3-double-deficient cells (Figure 4g). Increased processing of IL-1 by SMAC mimetic (BIR) was mediated by Caspase-8, as inhibition of Caspase- 8 by zIETD reduced the processing of IL-1 (Figure 4h).

\section{Combined deficiency of Caspase-1,11 and RipK3 results} in accelerated host fatality. The bacterial burden in Caspase-1,11-deficient mice was substantially higher than WT and RipK3-defiicent mice at day 7 post-infection (Figure 5a). We have previously reported that the bacterial burden of RipK3-deficient mice is similar to WT mice at day 5 post-infection with ST, and when RipK3-deficient macrophages are transferred to WT hosts, they mediate better protection. ${ }^{24}$ Interestingly, the bacterial burden of Caspase1,11-RipK3-double-deficient was even higher than Caspase1,11-deficient mice, with a significant number of doubledeficient mice becoming moribund by day 6 post-infection (Figure 5a). There was a graded impact of Caspase-1,11and RipK3-signalling on host survival, with Caspase-1,11signalling playing a dominant role. Furthermore, Caspase1,11-RipK3-double-deficient mice exhibited an earlier onset of susceptibility in comparison Caspase-1,11-deficient or RipK3-deficient mice (Figure 5b). These results indicate that RipK3 signalling plays a synergistic role in promoting control of ST. It has been previously reported that the bacterial burden in NLRC4-NLRP3-double-deficient mice is higher than WT mice, but similar to Caspase-1,11-deficient mice. ${ }^{25}$ Since our results indicate that bacterial burden in Caspase1,11-RipK3-double-deficient mice is substantially higher than the Caspase-1,11-deficient mice, this suggests that the impact of RipK3 that we have reported here may be independent of its possible role in NLRP3.

We evaluated the numbers of primed $\mathrm{CD}^{+} \mathrm{T}$ cells at day 7 post-infection of mice and observed a slightly reduced trend in Caspase-1,11-RipK3-double-deficient mice (Figure 5c) despite the bacterial burden being enormously high in this group of mice (Figure 5a). We evaluated whether the CD8 ${ }^{+}$ $T$ cells primed in the various groups of mice are functional in terms of cytolytic activity and expression of IFN- $\gamma$ in response to specific targets. Control (CFSE ${ }^{\text {low }}$ ) and OVA $_{257-264}$-pulsed (CFSE ${ }^{\text {hi }}$ ) spleen cells from naive mice were injected into mice that were infected with ST-OVA 6 days earlier. Owing to imminent fatality of the double-deficient mice, this experiment 

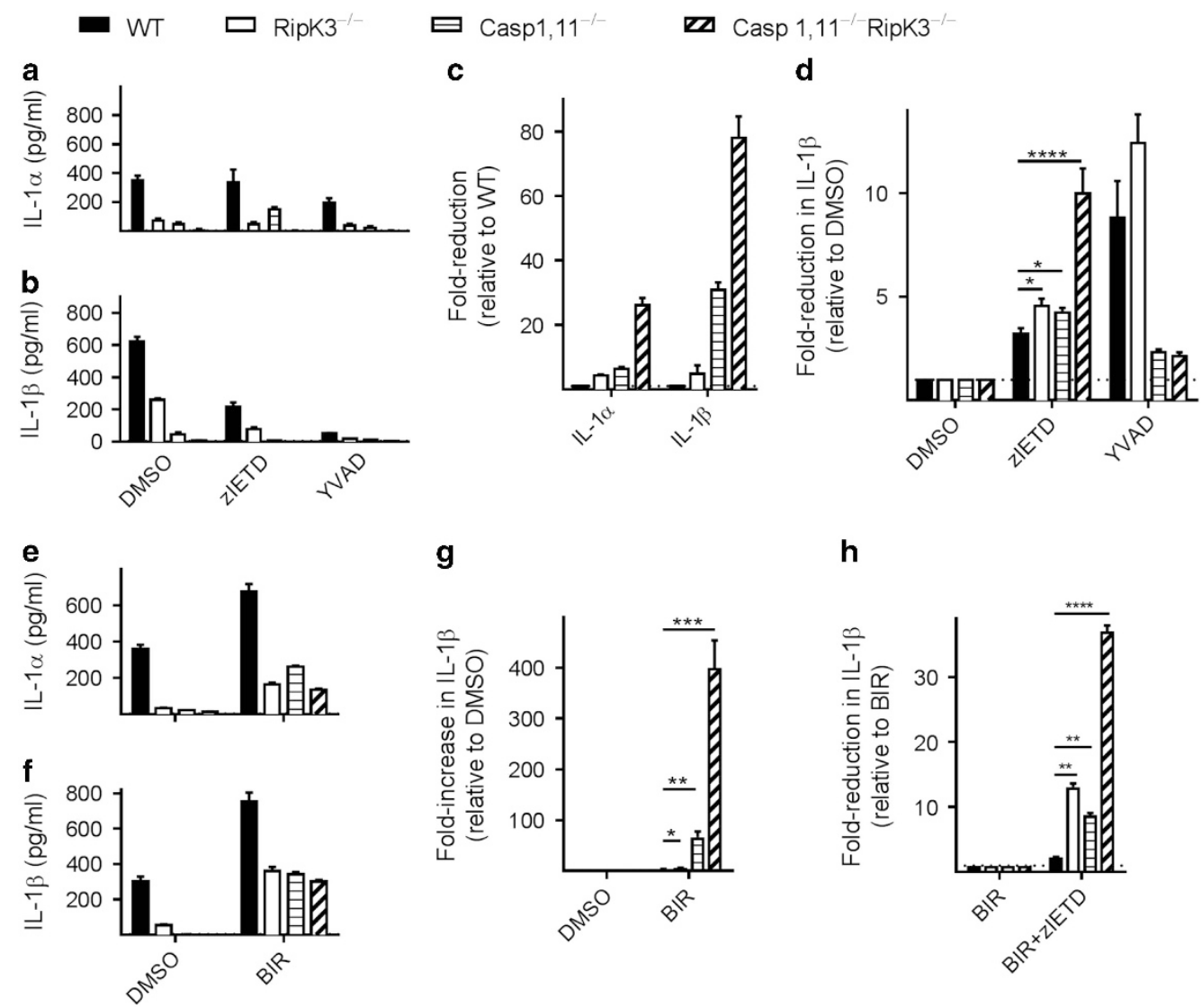

g

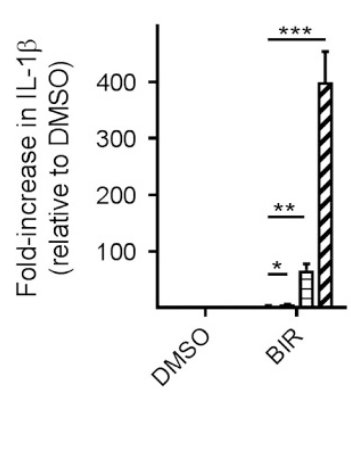

h

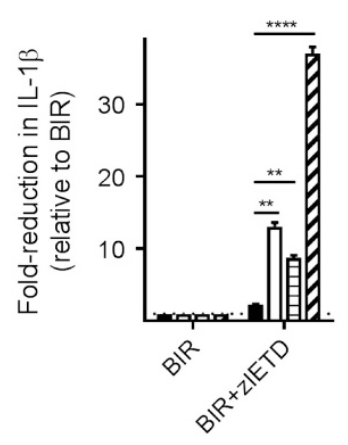

Figure 4 DCs from Caspase-1,11-RipK3-double-deficient mice display severe attenuation in processing of IL-1. (a,b) DCs from WT, RipK3 ${ }^{-/-}$, Caspase-1,11 ${ }^{-/-}$and

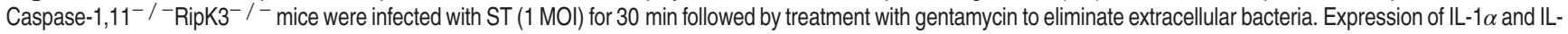
$1 \beta$ was measured in the supernatants collected at $24 \mathrm{~h}$ post-infection. (c) Fold-reduction in IL-1 $\alpha$ and IL-1 $\beta$ secretion in DCs was evaluated relative to the cytokine expression in WT cells. (d) Fold-reduction in IL-1 $\beta$ secretion following treatment with Caspase-8 inhibitor (ZIETD) and Caspase-1 inhibitor (YVAD) was calculated relative to DMSO control of

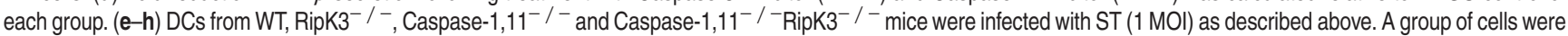
treated with the SMAC mimetic, Birinapant to induce degradation of cIAPs $(5 \mu \mathrm{M} \mathrm{BIR})$. Production of IL-1 $\alpha(\mathbf{e})$ and IL- $1 \beta(\mathbf{f})$ was measured in the supernatant collected at $24 \mathrm{~h}$ post-infection. Fold-increase in IL-1 $\beta$ production following BIR treatment was calculated relative to DMSO control of each group (g). Fold-reduction in IL-1 $\beta$ production by Caspase-8 inhibitor (zIETD) was calculated relative to BIR treatment of each group (h). ( $\left.{ }^{\star} P<0.05,{ }^{* \star} P<0.01,{ }^{* \star \star} P<0.0001\right)$

could not be performed at later time points. We observed potent, specific cytotoxity of $\mathrm{OVA}_{257-264}$-pulsed targets in all the four groups of mice (Figures $5 \mathrm{~d}$ and e). Interestingly, purified $\mathrm{CD}^{+} \mathrm{T}$ cells from the double-deficient mice expressed IFN- $\gamma$ even without stimulation by the $\mathrm{OVA}_{257-264^{-}}$ pulsed targets (Figures $5 f$ and g). Thus, these results indicate that the primed $\mathrm{CD}^{+} \mathrm{T}$ cells in double-deficient mice are functional in their ability to specifically kill target cells; however, they also show signs of dysfunction as revealed by spontaneous expression of IFN- $\gamma$.

Direct examination of spleens at day 7 post-infection was indicative of increased bacterial burden and consequent inflammation in Caspase-1,11-RipK3-double-deficient mice in comparison to Caspase-1,11-deficient mice (Figure 6a). Histological examination of spleens at day 7 post-infection revealed a graded impact on tissue pathology with Caspase-1,11-RipK3double-deficient mice having excessive tissue destruction in comparison to other mice (Figures $6 \mathrm{~b}$ and c). Interestingly, the splenic tissue in infected RipK3-deficient mice showed signs of hyperactivity of white pulp in comparison to WT spleens despite the bacterial burden being similar. Caspase-1,11-deficient mice had an even greater destruction of white-pulp, whereas Caspase-1,11-RipK3-double-deficient mice had extensive depletion of white-pulp and tissue architecture (Figures 6b and c). Expression of cytokines in the serum of infected mice collected at day 5 post-infection correlated with bacterial burden, except for IL-18, which was greatly impaired in Caspase-1,11-deficient and Caspase-1,11-RipK3-double-deficient mice (Figure 6d). A similar trend was noted in an endotoxin shock model where the expression of IL- $1 \beta$ and IFN $-\gamma$ was lowest in the serum of Caspase-1,11-RipK3-double-deficient mice (Supplementary Figure S4).

Combined deficiency of Caspase-1,11 and RipK3 results in increased inhibitory receptor expression in primed $\mathrm{CDB}^{+} \mathrm{T}$ cells. We evaluated the expression of various cell surface markers on primed $\mathrm{CD} 8^{+} \mathrm{T}$ cells at day 6 postinfection to determine the mechanism for the increased loss of primed $\mathrm{CD}^{+} \mathrm{T}$ cells in double-deficient mice (Figure 2g). Wild-type OT-1 TCR transgenic cells were adoptively transferred into various groups of mice as outlined in Figure $2 \mathrm{~d}$, and challenged with ST-OVA. The numbers of 

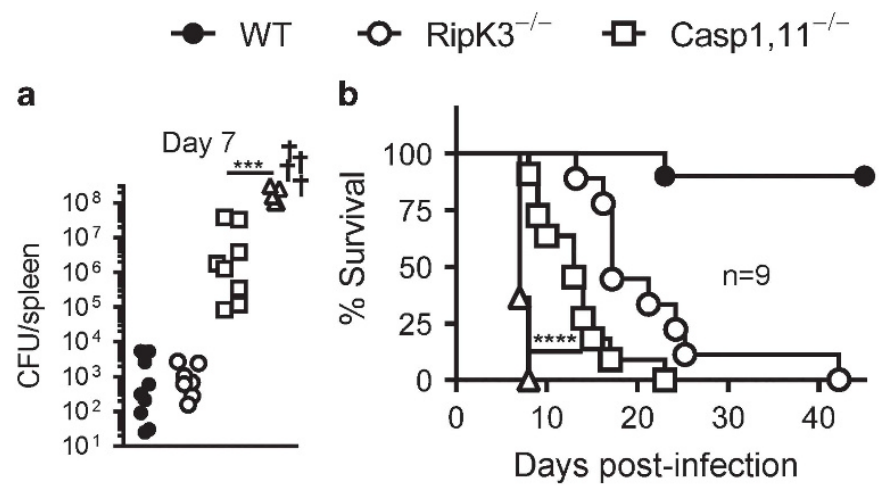

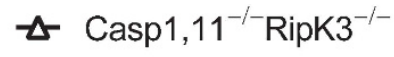
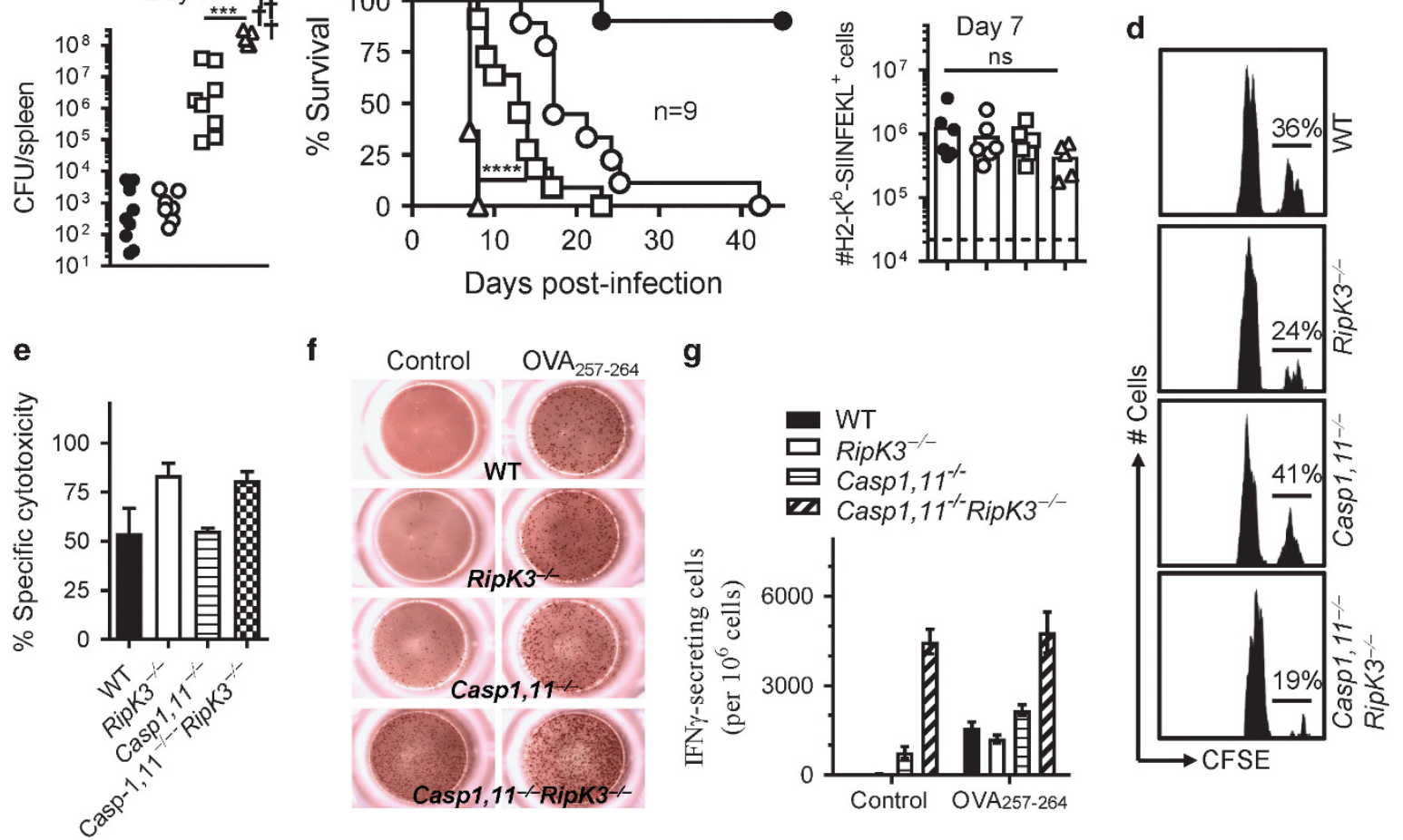

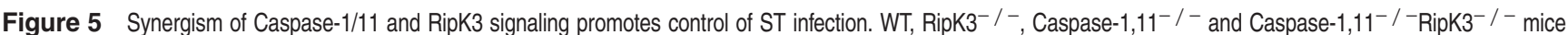
were infected with ST-OVA $\left(10^{3}\right.$, i.v.). On day 7 , bacterial burden was evaluated in the spleens of infected mice (a). Survival of infected mice was monitored for up to 60 days (b). The numbers of $\mathrm{OVA}_{257-264}$ (SIINFEKL)-specific CD8 ${ }^{+} \mathrm{T}$ cells were evaluated in the spleens of infected mice by staining with anti-CD8 antibody and H2-K $\mathrm{K}^{\mathrm{b}}-\mathrm{SIINFEKL}$ tetramers (c). Naive spleen cells (control- CFLE ${ }^{\text {low }}$ and $\mathrm{OVA}_{257-264}$-pulsed- CFSE $^{\text {hi }}$ ) were injected into mice that were infected with ST-OVA 6 days prior. At $24 \mathrm{~h}$ post spleen cell transfer, the fate of transferred cells was evaluated in the spleens of infected mice (d,e). Mice were infected as described above, and $\mathrm{CD} 8^{+} \mathrm{T}$ cells were purified on day 7 post-infection, and the expression of IFN $-\gamma$ evaluated by ELISPOT assay with/without $\mathrm{OVA}_{257-264}$ pulsed naive spleen cells $(\mathbf{f}, \mathbf{g})$. Data is shown as mean $\pm \mathrm{SEM}$ and is representative of $2-3$ separate experiments

memory precursor cells (MPEC, CD127 ${ }^{\text {hi } K L R G} 1^{\text {low }}$ ) at day 6 post-infection were compromised in Caspase-1,11-RipK3double-deficient mice (Figure 7a), which correlated with increased expression of the inhibitory receptors PD1 and TIM3 in primed OVA-specific CD8 ${ }^{+} \mathrm{T}$ cells (Figure 7a). In the same groups of mice, we evaluated the expression of activation markers in DCs and observed potent increase in the expression of MHC-II, CD80 and PDL1 in DCs of doubledeficient mice (Figure $7 \mathrm{~b}$ ). Thus, these results indicate that APCs in double-deficient mice are in a highly activated state, which correlates with increased bacterial burden in these mice, and consequently results in the expression of inhibitory receptors on primed $\mathrm{CD}^{+} \mathrm{T}$ cells.

Inflammatory cell death of APCs is necessary for maintenance of primed $\mathrm{CD8}^{+} \mathbf{T}$ cells. We evaluated the mechanism responsible for increased susceptibility of Caspase-1,11-RipK3-double-deficient mice. Administration of IL$1 \beta$ and IL-18 had opposing effects in the control of bacterial burden in Caspase-1,11-deficient and Caspase-1,11-RipK3double-deficient mice. While administration of IL-18 reduced the bacterial burden in both groups of mice to similar levels, injection of IL- $1 \beta$ resulted in exacerbation of bacterial burden particularly in Caspase-1,11-deficient mice (Figure 8a), indicating that the activation of $\mathrm{IL}-18$ is the critical innate immune mediator that is responsible for control of Salmonella infection. We observed that injection with a reduced dose of IL-18 (100 ng per mouse) in Caspase-1,11-deficient and Caspase-1,11-RipK3-double-deficient mice was sufficient to reduce the bacterial burden substantially (Figure $8 b$ ). Since the various groups of mice display substantial differences in bacterial burden at the peak of $\mathrm{CD}^{+}$T-cell response ( day 7 ), this creates complexity in the interpretation of the impact on $\mathrm{CD}^{+} \mathrm{T}$-cell response. We thus measured the expansion of adoptively transferred WT OT $-1 \mathrm{CD}^{+} \mathrm{T}$ cells in WT and Caspase-1,11-RipK3-double-deficient mice after IL-18 administration, which normalized the bacterial burdens in the two groups of mice. In PBS-treated groups, the numbers of transferred OT-1 CD8 ${ }^{+} \mathrm{T}$ cells were similar in WT and surviving Caspase-1,11-RipK3-double-deficient mice (Figure $8 \mathrm{c}$ ). This is despite the bacterial burden being $>10000$-fold higher in the double-deficient mice (Figure 5a). Interestingly, administration of IL-18, while slightly increasing the numbers of primed OT-1 CD8 ${ }^{+}$ $\mathrm{T}$ cells in WT mice, resulted in drastic reduction in the numbers of OT-1 $\mathrm{CD}^{+} \mathrm{T}$ cells in Caspase-1,11-RipK3- 
a
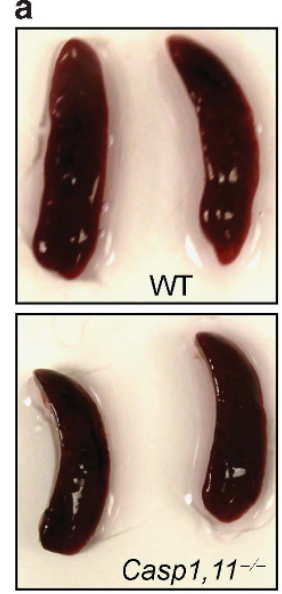

Casp1,11-

C

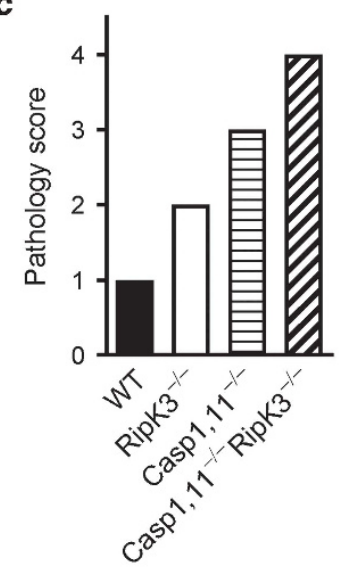

b
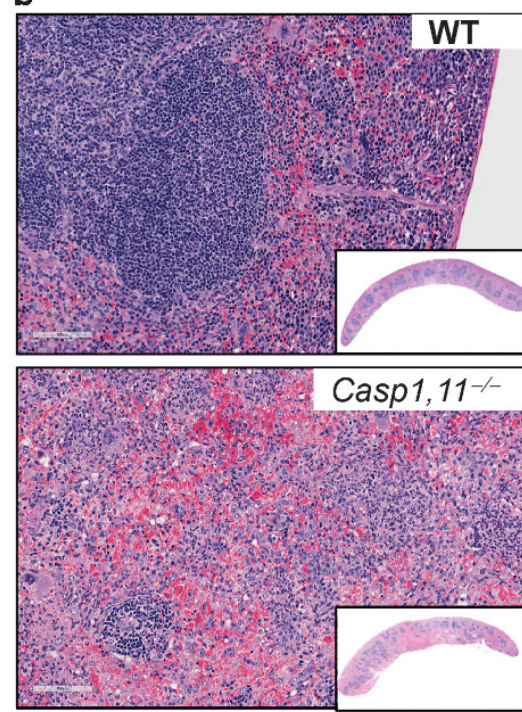
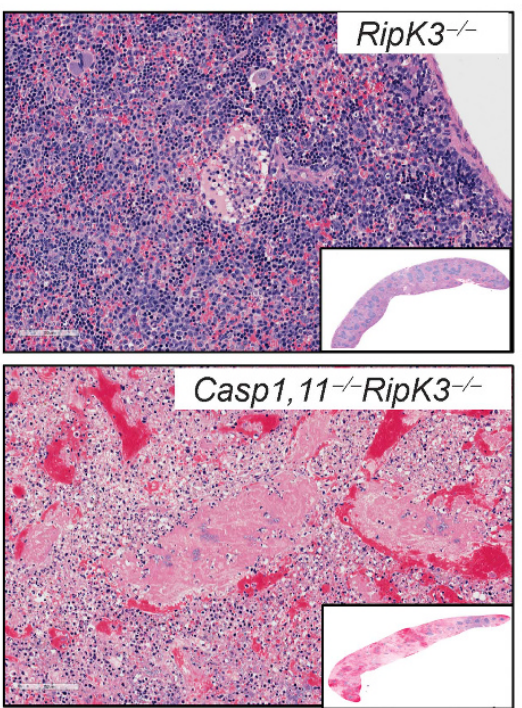

d
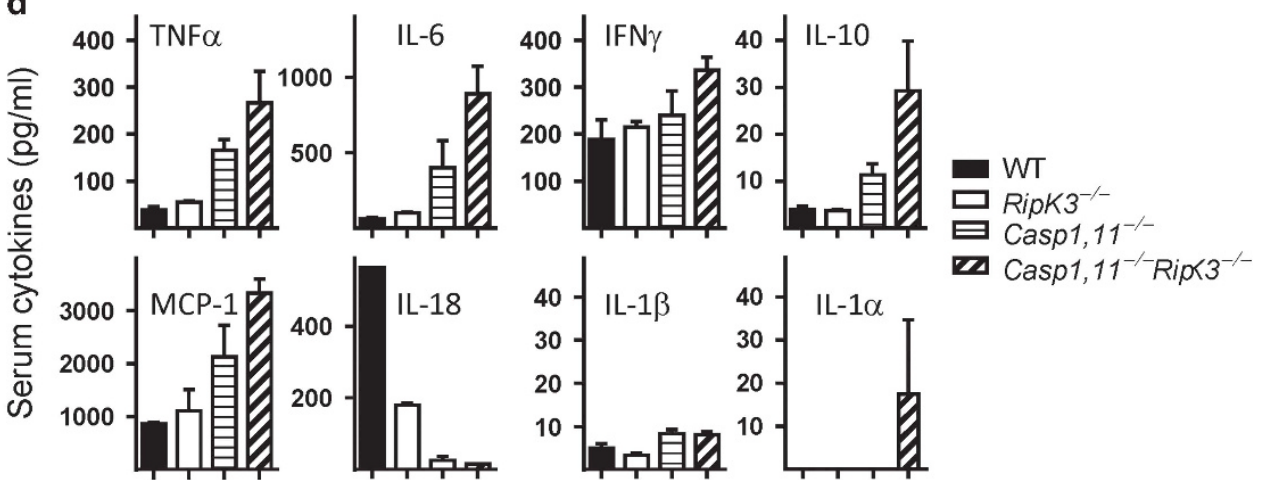

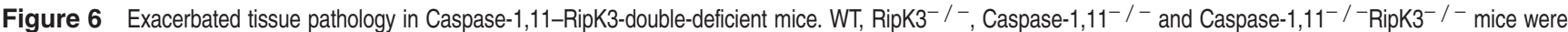
infected with ST-OVA as described in Figure 5. Representative images of spleens harvested from surviving mice at day-7 post-infection with ST-OVA are shown (a). Spleens were collected (day-7 post-infection) and treated with 10\% formalin and vertical sections were stained for hematoxylin and eosin (H\&E) (b) and the extent of pathology was scored (c). Serum was also collected at day- 5 post-infection and cytokine expression measured (d). The data are shown as mean \pm SEM and is representative of 2-3 separate experiments

double-deficient mice (Figures $8 \mathrm{c}$ and d), which correlated with potent reduction of bacterial burden (Figure 8e). We also purified OVA-specific CD8 ${ }^{+} \mathrm{T}$ cells at day 7 post-infection of WT and Caspase-1,11-RipK3-double-deficient mice using magnetic beads, and transferred the purified cells to naïve mice (Figure 8f). Primed $\mathrm{CD} 8^{+} \mathrm{T}$ cells from Caspase-1,11RipK3-double-deficient mice displayed a major defect in survival upon transfer to naive recipients (Figures $8 g$ and $h$ ).

Taken together, these results indicate that Caspase-1, 11 - and RipK3- signalling mechanisms synergize to induce cell death and processing of IL-1/IL-18. While IL-18 promotes innate control of the bacterium, cell death by these pathways limits the inhibitory receptor expression in primed $\mathrm{CD} 8^{+} \mathrm{T}$ cells, and allows the generation of memory precursor cells, which would eventually differentiate to memory cells (Figure 9).

\section{Discussion}

$\mathrm{CD}^{+} \mathrm{T}$-cell differentiation is governed by the three signals: MHC-peptide, cell surface co-stimulatory molecules and cytokines such as IL-12 and IFN-I. ${ }^{26}$ While the response cannot be elicited without the MHC-peptide-TCR interaction, the engagement of co-stimulatory or co-inhibitory signals governs the magnitude of the response elicited. ${ }^{27-29}$ The molecular mechanisms that modulate the magnitude of response during T-cell differentiation are not clear. We considered the possibility that early death of antigenpresenting cells by inflammatory cell death pathways may significantly influence the differentiation of $\mathrm{CD} 8^{+} \mathrm{T}$ cells. Our results indicate that during infection with ST, antigenpresenting cells must be rapidly culled by both the Caspase $-1,11$ and RipK3 pathways to prevent the primed CD8 ${ }^{+}$ $T$ cells from expressing inhibitory receptors (PD-1, TIM3) and become dysfunctional.

Inflammatory host cell death is a mechanism that, in contrast to apoptosis, results in cell-rupture and release of DAMPs to the external milieu, which promotes systemic inflammation. ${ }^{13,18}$ Inflammatory cell death is considered as a key mechanism of pathogen-virulence. ${ }^{30}$ Since cell death of DCs has been considered as a mechanism of immune 
a

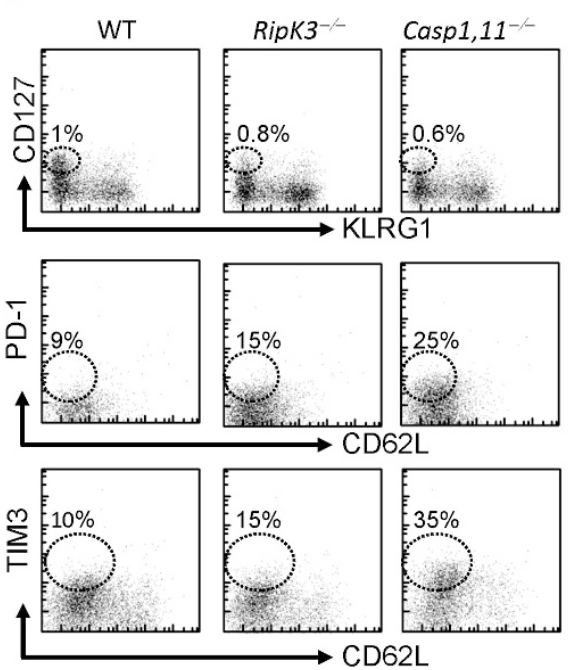

Casp1,11--

$\operatorname{RipK3}^{-1}$
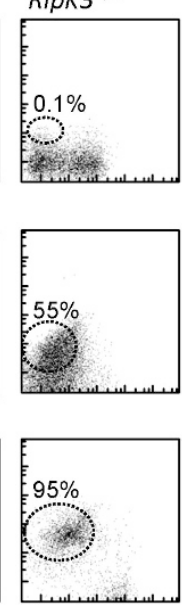
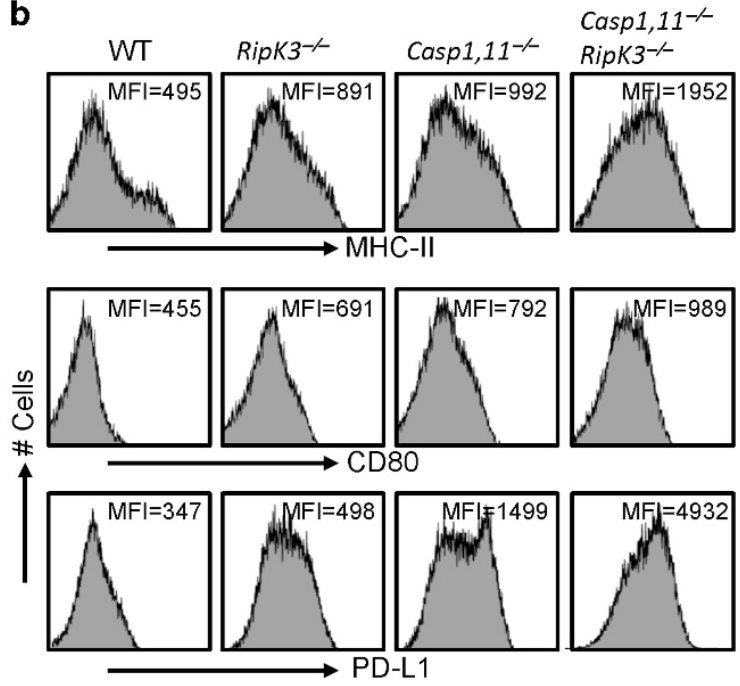

Figure 7 Inflammatory cell death pathways restrict the expression of inhibitory receptors on primed CD8 ${ }^{+} \mathrm{T}$ cells. OT- $1 \mathrm{CD} 8^{+} \mathrm{T}$ cells $\left(\mathrm{CD} 45.1^{+} \mathrm{CD} 45.2^{+}\right)$were injected (iv, $10^{5}$ per mouse) into WT, RipK3-, Caspase-1,11- and Caspase-1,11-RipK3-deficient mice (all CD45.2 $2^{+}$) followed by infection of recipient mice with ST-OVA (10 ${ }^{3}$, i.v.) the next day. At day- 6 post-infection, OT-1 cells $\left(C D 45.1^{+}\right)$were tracked in the spleens of infected recipient mice $\left(C D 45.1^{-} C D 45.2^{+}\right)$, and the expression of various inhibitory cell surface molecules evaluated (a). The expression of various activation/inhibitory molecules was also tracked in endogenous DCs at day 6 post-infection (b). The data are shown as mean \pm SEM and is representative of 2-3 separate experiments

a

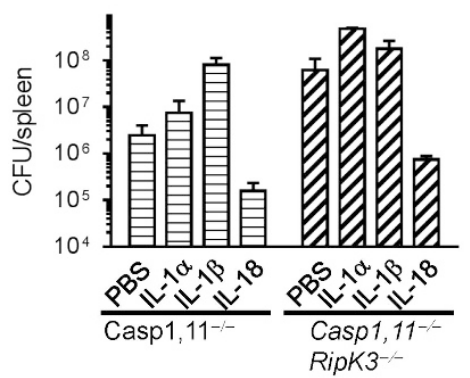

b

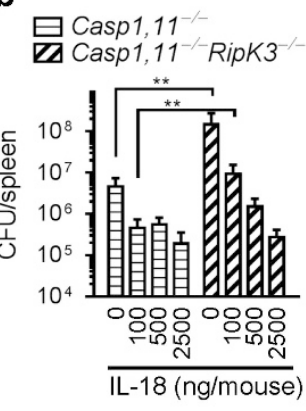

c

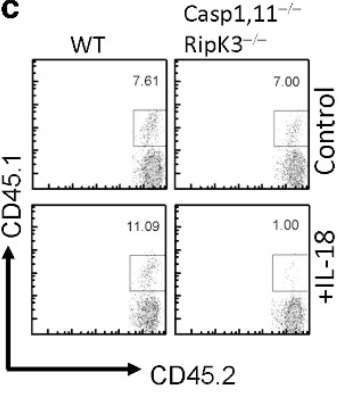

d

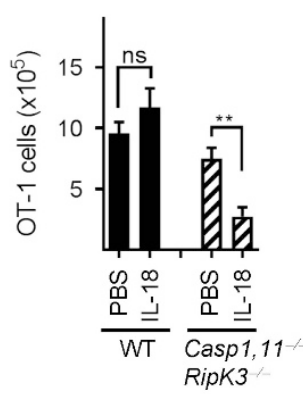

e

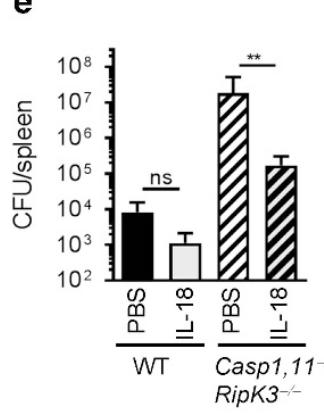

f WT
Casp1,11-RipK3-- g

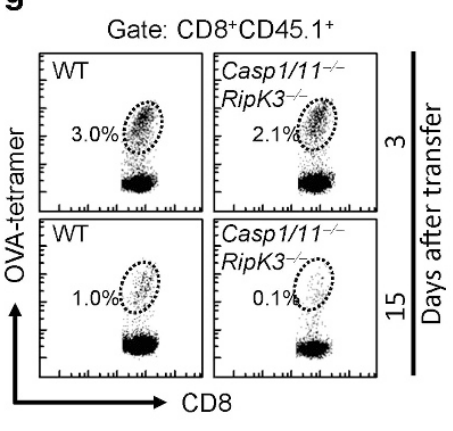

h

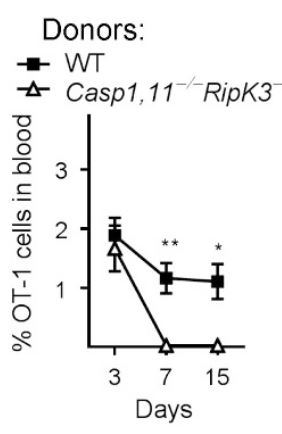

Figure 8 Absence of Caspase-1,11 and RipK3 signaling compromises the survival of primed CD8 ${ }^{+} \mathrm{T}$ cells in a cell extrinsic manner. (a) Mouse recombinant IL-1 $\alpha$ (100 ng

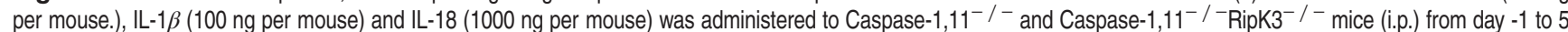
post-infection with ST-OVA $\left(10^{3}\right.$ i.v.). Spleens were obtained from infected mice on day 6 post-infection, and the bacterial burden evaluated. (b) Different doses of IL-18 were

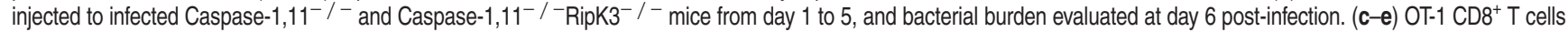
$\left(\mathrm{CD} 45.1^{+} \mathrm{CD} 45.2^{+}\right)$were injected $\left(10^{4}\right.$, i.v.) into WT and Caspase-1,11-RipK3-double-deficient mice. Mice were infected with ST-OVA as described above. A group of mice received IL-18 (1000 ng per mouse) as indicated above. At day 7 post-infection, the numbers of donor OT-1 (CD45. $\left.1^{+} \mathrm{CD} 45.2^{+}\right)$(c,d) and bacterial burden (e) were evaluated in the spleens of infected recipient (CD45. $\left.1^{-} \mathrm{CD} 45.2^{+}\right)$mice. $(\mathrm{f}-\mathrm{h}) \mathrm{OT}-1$ cells $\left(\mathrm{CD} 45.1^{+} \mathrm{CD} 45.2^{+}\right)$were transferred into WT and Caspase-1,11-RipK3-double-deficient mice, which were then infected with ST-OVA as described above. At day 7 post-infection, spleens were removed from infected mice, and the OVA-specific CD8 ${ }^{+} \mathrm{T}$ cells purified by staining with OVA-tetramers, biotin anti-CD45.1 followed by isolation with streptavidin magnetic beads. Purified cells from WT and Caspase-1,11-RipK3-double-deficient mice were then transferred into naive WT mice and the numbers of these cells evaluated in the blood at various time intervals post-transfer. The data shown are representative of 2-3 separate experiments. Statistical significance was determined by unpaired student $t$-test $\left({ }^{*} P<0.05,{ }^{* \star} P<0.01\right)$ 


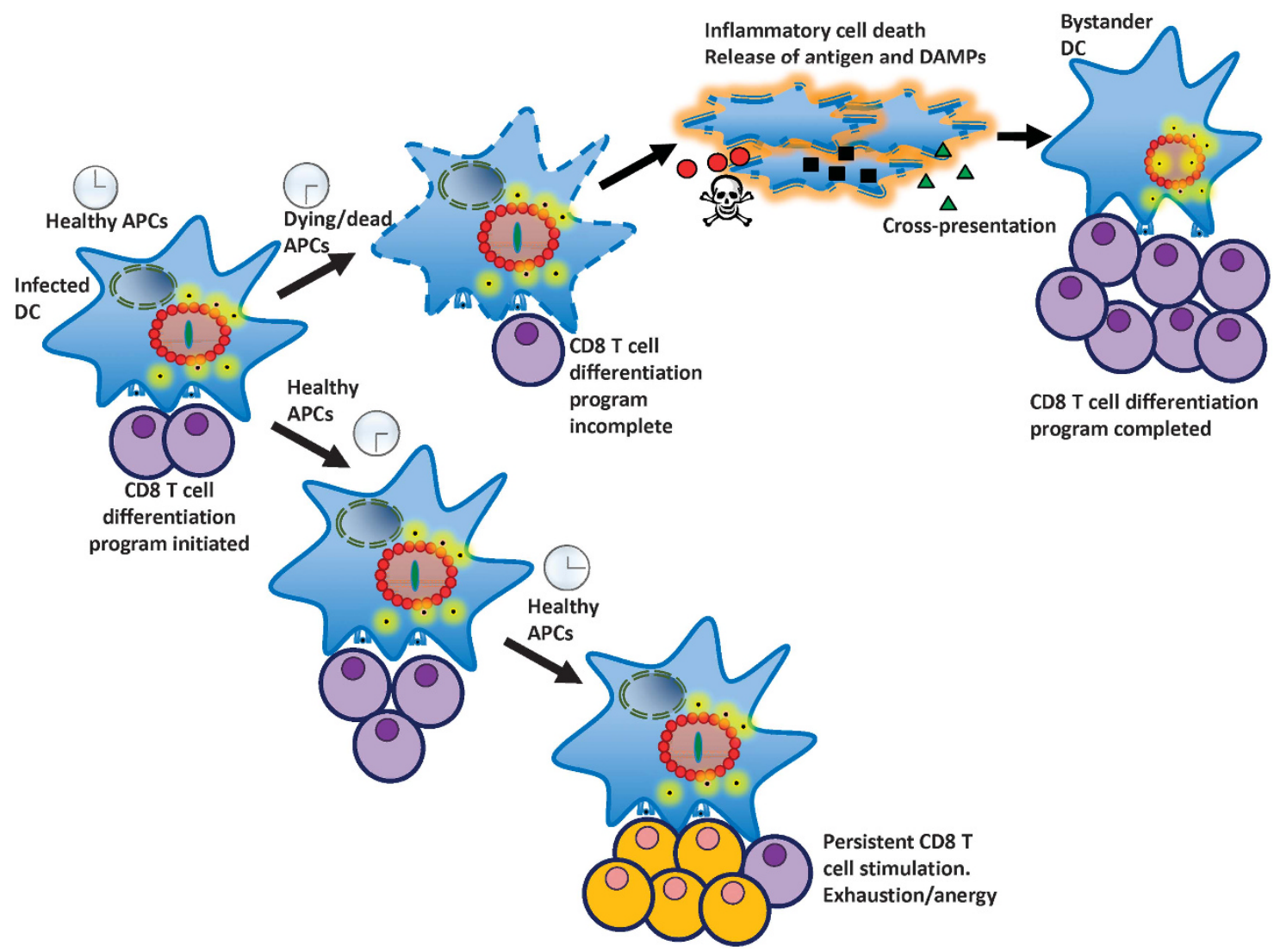

Figure 9 Prolonged survival of infected APCs compromises CD8 ${ }^{+}$T-cell priming. APCs must be rapidly eliminated by inflammatory cell death pathways in order to prevent persistent APC-CD8 ${ }^{+}$T-cell interactions, which would lead to overstimulation and dysfunction of $C D 8^{+} \mathrm{T}$ cells

evasion, ${ }^{31}$ we evaluated whether this impacts antigenpresentation and $\mathrm{CD}^{+}{ }^{+}$-cell differentiation. Herein, we have disabled two important mechanisms of cell death, induced by Caspase-1,11 and RipK3, and show that these pathways synergize to promote inflammatory cell death of APCs and processing of IL-1/18. Furthermore, early death of APCs is necessary to promote the differentiation and survival of CD8 ${ }^{+}$ T cells that express reduced levels of PD-1 and display better survival properties. It has been previously reported that PD-1 is highly expressed on dysfunctional $\mathrm{CD}^{+} \mathrm{T}$ cells, and blockade of PD-1 signaling can restore $\mathrm{CD}^{+}{ }^{+}$-cell responses. ${ }^{32}$ Thus, our results suggest that the lack of inflammatory cell death of APCs results in differentiation of $\mathrm{CD} 8^{+} \mathrm{T}$ cells towards a dysfunctional phenotype with poor survival properties.

We have previously reported that the rapid death of allogenic APCs by activated $\mathrm{CD}^{+} \mathrm{T}$ cells restricts the full activation of $C D 8^{+} \mathrm{T}$ cells in vitro. ${ }^{33}$ Since that study was done in vitro with allogenic APCs, we tested this paradigm in an in vivo infection model in the current study. Intracellular pathogens readily infect and eliminate APCs before CD8 ${ }^{+}$ T cells become functionally efficient at killing APCs. ${ }^{11,14,15}$ The relative duration of $\mathrm{DC}$-T-cell interaction that is sufficient to prime $\mathrm{CD}^{+} \mathrm{T}$ cell is not clear. Although initial studies indicated that a prolonged interaction may be required, ${ }^{34}$ other studies have shown that the interactions are dynamic, short-lived and sequential. ${ }^{35}$ It is likely that the interactions are short-lived, owing to premature death of APCs by inflammatory cell death pathways. Phagosomal pathogens such as ST and Mycobacteria are known to induce rapid death of APCs, and bystander DCs have been shown to pick up the debris and present antigen to $\mathrm{CD}^{+} \mathrm{T}$ cells through cross-presentation. ${ }^{36,37} \mathrm{CD}^{+}$ T-cell activation can occur via 'cross-presentation' through multiple mechanisms, ${ }^{38-41}$ and this may have evolved as a mechanism to ensure that $\mathrm{CD}^{+} \mathrm{T}$ cells receive sufficient stimulation in the face of premature death of APCs.

Naive $\mathrm{CD}^{+} \mathrm{T}$ cells are not cytolytic, but as they differentiate, they become fully capable of killing antigen-bearing APCs. ${ }^{33}$ This is another important mechanism that serves to restrict the persistence of antigen-bearing APCs in order to prevent overstimulation of primed $\mathrm{CD}^{+} \mathrm{T}$ cells. The inflammatory death of APCs that we have described here operates at much earlier time intervals, so this could have an impact from earlier time points, and may be more relevant in the context of chronic infection.

RipK1 is a key protein that drives necrosome signaling, leading to cell death by necroptosis. ${ }^{13}$ The impact of RipK1 in NF-kB signaling of myeloid cells is not clear. ${ }^{42-44}$ Recently, RipK1 signaling in dying cells was shown to promote crosspriming of $\mathrm{CD}^{+} \mathrm{T}$ cells in the context of tumor immunity, which was due to the impact of RipK1 on NF-kB signaling. ${ }^{45}$ Interestingly, our results indicate that in the context of a pathogen, disabling of RipK3 or Caspase-1/11 separately did not diminish antigen presentation by DCs. Disabling of both of these signaling molecules was required for revelation of the negative impact on the survival of primed $C D 8^{+} \mathrm{T}$ cells through 
increased expression of inhibitory receptors such as PD-1 and TIM3. Our results indicate that in the context of infection, inactivation of RipK3 or Caspase-1/11 does not have any impact on NF-kB or MAPK signaling in DCs.

Caspase-1,11-signaling is a key mechanism of cell death during infection with ST. ${ }^{46,47}$ We have previously shown that RipK3-deficient macrophages also undergo reduced celldeath following infection with $S T^{14}$ Similarly, disabling the kinase function of RipK1 by K45A mutation in macrophages resulted in reduced cell death and IL- $1 \beta$ expression following infection with ST. ${ }^{42}$ Our results indicate that Caspase-1,11 is more dominant than RipK3 in inducing the cell death of DCs. Furthermore, Caspase-1,11-RipK3-double-deficient DCs display complete resistance to cell death. These results were further corroborated by analyzing IL-1a secretion, which is an 'alarmin' that is released only by dying cells. ${ }^{19}$ While we have used total knockouts of Caspase-1,11-, RipK3- and Caspase1,11-RipK3, the impact of myeloid cell-specific deficiency of these proteins in host survival during infection is not clear. We have previously reported that RipK3-deficient mice did not show any impact on the ST burden at day 5 post-infection; however, when RipK3-deficient macrophages were transferred to WT hosts, they displayed slightly better control of ST, possibly by surviving longer and phagocytosing ST in vivo. ${ }^{24}$ Thus, the impact of total body knockouts of these genes versus myeloid cell-specific deletion warrants further investigation.

While the activation/processing of IL-1 cytokine family promotes protection against pathogens, ${ }^{48}$ cell death has also been shown to limit pathogen spread through release of intracellular bacteria for uptake and killing by neutrophils, independently of IL-1 $\beta$ and IL-18. ${ }^{46}$ Furthermore, upon cell rupture, any non-processed pro - IL-1 $\beta$ and pro - IL-18 could potentially be processed by extracellular proteases. ${ }^{49}$ Our results indicate that the secretion of processed IL-18 is the critical protective innate immune mechanism following Caspase-1/11-RipK3 signalling, independent of cell death. However, the "fitness" of CD8 ${ }^{+}$T-cell differentiation program was governed by cell death of APCs, not IL-18 expression.

NLRC4 and NLRP3 inflammasomes have been shown to play a redundant role in promoting the control of $\mathrm{ST}^{25}$ as the bacterial burden in NLRC4-NLRP3-double-deficient mice was higher than WT mice, but similar to Caspase-1,11-deficient mice. $^{25}$ Our results indicate that the bacterial burden in Caspase-1,11-RipK3-double-deficient mice is substantially higher than that observed in Caspase-1,11-deficient mice. This suggests that the impact of Caspase-1,11-RipK3-double deficiency is substantially greater than that of NLRC4NLRP3-double deficiency. Therefore, the impact of RipK3 cannot be explained solely based on its potential interaction with NLRP3. It is conceivable that the interaction of RipK3 with MLKL or other unknown interacting proteins impacts the processing of IL-1 $\beta$. There appears to be a substantial crosstalk between ripoptosome, necrosome and inflammasome signaling platforms that results in inflammatory cell death through Caspase-1/RipK1/RipK3/Caspase-8 signaling. ${ }^{20,50-53}$ In contrast to this, Caspase-8 was shown to limit NLRP3 inflammasome activation, which was dependent on various members of the necrosome. ${ }^{54,55}$ Our results indicate that while Caspase-1 promotes the processing of IL-
$1 \beta$ only in WT and RipK3 ${ }^{-/-}$DCs, Caspase- 8 promotes the processing of IL-1 $\beta$ in WT, Caspase1,11-/- and RipK3 ${ }^{-/-}$ DC's to the same degree. Furthermore, Caspase- 8 activity was critical in promoting $\mathrm{IL}-1$ processing of Caspase-1RipK3-double-deficient DCs.

Overall, we have revealed various pathways through which Caspase-1, Caspase-8 and RipK3 participate in promoting inflammatory cell death of APCs and activation of innate and acquired immune response. Killing of APCs by Caspase-1,11 and RipK3 pathways ensures extinction of continued CD8 ${ }^{+}$ T-cell activation during the initial periods, which limits the development of $\mathrm{CD}^{+} \mathrm{T}$ cells with a dysfunctional phenotype. These results open up avenues in situations where antigen presentation persists and inflammatory cell death pathways may be dysfunctional such as in cancers or chronic infections. Activation of inflammatory cell death pathways may lead to the differentiation of $\mathrm{CD}^{+} \mathrm{T}$ cells with better functional and survival capabilities.

\section{Materials and Methods}

Mice. C57BL/6 mice were purchased from Jackson Laboratory (Bar Harbor, ME, USA). Caspase-1,11-deficient mice were provided by Richard Flavell (Yale University). RipK3-deficient mice were provided by Vishva Dixit (Genentech, San Francisco, CA, USA). Caspase-1,11-deficient mice were mated with RipK3-deficient mice to generate Caspase-1,11-RipK3-double-deficient mice. CD45. $1^{+} 45.2^{+}$OT-1 mice were generated by mating OT-1 males $\left(45.1^{-} 45.2^{+}\right)$with B6.SJL $\left(C D 45.1^{+} 45.2^{-}\right)$females. All animal experiments were performed in the animal facility at the University of Ottawa, as per Canadian Council on Animal Care (CCAC) guidelines. End points were determined by $20 \%$ drop in body weight.

Bacteria and infection. Recombinant ST strain (SL1344) that induces antigen (OVA) expression into the cytosol of infected cells (ST-OVA) have been previously described. ${ }^{56}$ Bacteria were diluted in $0.9 \% \mathrm{NaCl}$ and injected in $100 \mu \mathrm{l}$ via the lateral tail vein (intravenously). Bacterial burdens were evaluated by plating serial dilutions of homogenates on brain heart infusion plates.

DCs. Bone marrow-derived DCs (BMDCs) were grown in-vitro as previously described after culturing cells with GM-CSF (5 ng/ml, Empire Genomics, New York, NY, USA). ${ }^{57}$ Splenic DCs were purified using PE-CD11c positive selection (Stemcell, Vancouver).

Infection and cell death assay. DCs were plated onto 96-well plate at a concentration of $10^{5}$ cells per well, and infected with ST (10 MOI). After $30 \mathrm{~min}$, cells were washed and incubated in RPMl $+8 \% \mathrm{FBS}(\mathrm{R} 8)+$ gentamycin $(50 \mu \mathrm{g} / \mathrm{ml})$. At $2 \mathrm{~h}$, cells were washed again and incubated for 16-24 $\mathrm{h}$ with R8+gentamycin $(10 \mu \mathrm{g} / \mathrm{ml})$. Neutral red dye (Sigma, St. Louis, MO, USA) was added to cells for $10-15 \mathrm{~min}$ and evaluated for uptake by viable cells as previously described. ${ }^{14}$

Cytokine quantification. Serum samples and supernatants were collected and the expression of IL- $1 \alpha, \mathrm{IL}-1 \beta, \mathrm{TNF} \alpha, \mathrm{IL}-6$ and IL-10 were evaluated using cytokine bead array (BD Biosciences, San Jose, CA, USA). Expression of IL-18 was evaluated using the ProcartaPlex multiplex immunoassay kit (eBioscience, San Diego, CA, USA).

In-vitro antigen-presentation assay. $\mathrm{CD} 8^{+} \mathrm{T}$ cells were labelled with $0.125 \mu \mathrm{M}$ CFSE in PBS at $37^{\circ} \mathrm{C}$ for $8 \mathrm{~min}$ at a concentration of $2 \times 10^{7}$ splenocytes per $\mathrm{ml}$. The reaction was stopped by adding equal volume of equine serum and placed on ice for $5 \mathrm{~min}$, followed by numerous washes with PBS. Cells were plated at $5 \times 10^{4}$ cells per well on a round bottom 96-well plate in R8 medium. Cells were infected with bacteria for 30- min followed by three washes and a $2 \mathrm{~h}$ treatment with gentamycin $(50 \mu \mathrm{g} / \mathrm{ml})$. These cells were then incubated with $5 \times 10^{4} \mathrm{CFSE}$ labeled, purified OT-1 $\mathrm{CD}^{+} \mathrm{T}$ cells using a negative selection kit, and cells were cultured in $\mathrm{RPMl}+8 \% \mathrm{FBS}$ including gentamycin $(5 \mu \mathrm{g} / \mathrm{ml})$. Proliferation of $\mathrm{CD}^{+} \mathrm{T}$ cells was evaluated at various time intervals.

Adoptive transfer. CD8 ${ }^{+}$OT- 1 cells were purified from splenocytes of OT-1 mice $\left(\mathrm{CD} 45.1^{+} \mathrm{CD} 45.2^{+}\right)$using a $\mathrm{CD}^{+}$negative selection kit from Stemcell 
Technologies (Vancouver, BC, Canada). $10^{5}$ CD8 ${ }^{+}$OT-1 cells were then injected i.v. into recipient mice (CD45. $1^{-} \mathrm{CD} 45.2^{+}$) one day prior to ST infection. Blood samples were collected using saphenous bleeding, or mice were killed and splenocytes were collected at various time points and assessed for the numbers of transferred $\mathrm{CD} 45.1^{+} \mathrm{CD} 45.2^{+}$cells in the $\mathrm{CD} 8^{+} \mathrm{T}$-cell population by flow cytometry.

Antibodies and other reagents. Anti-CD8 $\alpha$ (53-6-7), anti-CD11b (M170), anti-CD11C (HL3), anti-CD19 (1D3), anti-CD45.1 (A20), anti-CD45.2 (104), antiB220 (RA36B2), anti-CD80 (No. 17-0801-82), anti-CD86 (No. 11-0860-81), anti-TCR $\beta$ (No. 12-5961-82), antiPDL1 (No. 740614), anti-PDL2 (No. 741026), anti-KLRG1 (No. 11-5893-80), anti-CD62L (No. 25-0621-82) and anti-CD127 (No. 17-1271-82) antibodies were purchased from eBioscience (San Diego, CA, USA). Anti-mouse-IA/IE (M5/114.15.2) and anti-TIM3 antibodies were purchased from Biolegend (San Diego, CA, USA). Anti-mouse PD-1 (No. 744548) was obtained from BD Biosciences (USA). H2-K $K^{b}$-SIINFEKL Dextramer was obtained from Immudex (Copenhagen, Denmark). Pan-caspase inhibitor ZVAD-fmk was obtained from Calbiochem (San Diego, CA, USA). Caspase-1 inhibitor YVAD was obtained from Calbiochem (San Diego, CA, USA). Caspase-8 inhibitor zIETD-fmk was obtained from Biovision (San Francisco, CA, USA). SMAC mimetic Birinapant was obtained from Selleckchem (Houston, TX, USA). Carboxyfluresceine succinimidyl ester (CFSE) was obtained from Sigma. Mouse recombinant IL-1 $\alpha$ and IL-1 $\beta$ were obtained from R\&D (Minneapolis, MN, USA). Mouse recombinant IL-18 was obtained from MBL (Woburn, MA, USA).

Western blotting. Samples were lysed using SDS/ $\beta$-ME buffer, and subjected to SDS-PAGE. Samples were transferred onto PVDF membranes and probed using either ECL or Femto substrates from Life Technologies (Carlsbad, CA, USA) and developed using X-ray. The following antibodies were obtained from Cell Signaling Tech. (Beverly, MA, USA): Rabbit anti-p65 NF-kB (D14E12), rabbit anti-pp65 NF-kB (93H1), rabbit anti-p38 MAPK (D13E1), and rabbit anti-pp38 MAPK (T180/Y182). Additional antibodies were purchased from the following sources: Mouse anti-RipK1 (38/RIP) from BD Biosciences, Rat anti-Caspase-8 (1G12) from Enzo (Farmingdale, NY, USA), Rabbit anti-Ipaf/NLRC4 (06-1125) from EMD Milipore (Bilerica, MA, USA), Rat anti-NLRP3 (768319) from R\&D System, (Minneapolis, MN, USA), Rabbit anti-IL-18 (5180 R-100) from Biovision (Milpitas, CA, USA), Mouse anti-actin (ACTBD11B7) from Santa Cruz (Dallas, TX, USA), Rabbit anti-RipK3 (2283) from ProSci (Poway, CA, USA) and Rabbit anti-clAP1/2 (CY-P1041) from Cyclex (Nagano, Japan).

Histology. Spleens were collected from infected mice and fixed in neutral buffer $10 \%$ formalin for $48 \mathrm{~h}$ followed by treatment in $70 \%$ ethanol. Spleens were then embedded in parafilm and vertical sections were stained with hematoxylin and eosin (H\&E) to assess pathology.

\section{Conflict of Interest}

The authors declare no conflict of interest.

Acknowledgements. This work was supported by an Operating Grant from the Canadian Institutes of Health Research (SS) and a grant from the National Institutes of Health (NIH) to LK (RO1Al101049). RP was supported by doctoral awards from the Ontario Graduate Scholarship and the Fonds de la recherche en santé Québec.

\section{Author contributions}

$\mathrm{RP}$ performed experiments, analyzed the data and wrote the manuscript. BS, KK and KW performed experiments. LK provided valuable research reagents. SS designed experiments and edited the manuscript.

1. Iwasaki A, Medzhitov R. Control of adaptive immunity by the innate immune system. Nat Immunol 2015; 16: 343-353.

2. Kaech SM, Ahmed R. Memory CD8 + T cell differentiation: initial antigen encounter triggers a developmental program in naive cells. Nat Immunol 2001; 2: 415-422.

3. Badovinac VP, Porter BB, Harty JT. Programmed contraction of CD8(+) T cells after infection. Nat Immunol 2002; 3: 619-626.

4. Allison JP. CD28-B7 interactions in T-cell activation. Curr Opin Immunol 1994; 6: 414-419.
5. Ha SJ, Mueller SN, Wherry EJ, Barber DL, Aubert RD, Sharpe AH et al. Enhancing therapeutic vaccination by blocking PD-1-mediated inhibitory signals during chronic infection. J Exp Med 2008; 205: 543-555.

6. Monack DM, Mueller A, Falkow S. Persistent bacterial infections: the interface of the pathogen and the host immune system. Nat Rev Microbiol 2004; 2: 747-765.

7. Dhanoa A, Fatt QK. Non-typhoidal Salmonella bacteraemia: epidemiology, clinical characteristics and its' association with severe immunosuppression. Ann Clin Microbiol Antimicrob 2009; 8: 15.

8. Scanu T, Spaapen RM, Bakker JM, Pratap CB, Wu LE, Hofland I et al. Salmonella manipulation of host signaling pathways provokes cellular transformation associated with gallbladder carcinoma. Cell Host Microbe 2015; 17: 763-774.

9. Vidal SM, Malo D, Vogan K, Skamene E, Gros P. Natural resistance to infection with intracellular parasites: isolation of a candidate for Bcg. Cell 1993; 73: 469-485.

10. Kaczmarek A, Vandenabeele $P$, Krysko DV. Necroptosis: the release of damage-associated molecular patterns and its physiological relevance. Immunity 2013; 38: 209-223.

11. Broz P, Monack DM. Molecular mechanisms of inflammasome activation during microbial infections. Immunol Rev 2011; 243: 174-190.

12. Vandenabeele P, Galluzzi L, Vanden Berghe T, Kroemer G. Molecular mechanisms of necroptosis: an ordered cellular explosion. Nat Rev Mol Cell Biol 2010; 11: 700-714.

13. Duprez L, Takahashi N, Van HF, Vandendriessche B, Goossens V, Vanden Berghe T et al. RIP kinase-dependent necrosis drives lethal systemic inflammatory response syndrome. Immunity 2011; 35: 908-918.

14. Robinson N, McComb S, Mulligan R, Dudani R, Krishnan L, Sad S. Type I interferon induces necroptosis in macrophages during infection with Salmonella enterica serovar Typhimurium. Nat Immunol 2012; 13: 954-962.

15. Upton JW, Kaiser WJ, Mocarski ES. Virus inhibition of RIP3-dependent necrosis. Cell Host Microbe 2010; 7: 302-313.

16. Cho YS, Challa S, Moquin D, Genga R, Ray TD, Guildford M et al. Phosphorylation-driven assembly of the RIP1-RIP3 complex regulates programmed necrosis and virus-induced inflammation. Cell 2009; 137: 1112-1123.

17. Christofferson DE, Yuan J. Necroptosis as an alternative form of programmed cell death. Curr Opin Cell Biol 2010; 22: 263-268.

18. Declercq W, Vanden Berghe T, Vandenabeele P. RIP kinases at the crossroads of cell death and survival. Cell 2009; 138: 229-232.

19. Dinarello CA. Immunological and inflammatory functions of the interleukin-1 family. Annu Rev Immunol 2009; 27: 519-550.

20. Maelfait J, Vercammen E, Janssens S, Schotte P, Haegman M, Magez S et al. Stimulation of Toll-like receptor 3 and 4 induces interleukin-1beta maturation by caspase-8. J Exp Med 2008; 205: 1967-1973.

21. Labbe K, Mclntire CR, Doiron K, Leblanc PM, Saleh M. Cellular inhibitors of apoptosis proteins CIAP1 and CIAP2 are required for efficient caspase-1 activation by the inflammasome. Immunity 2011; 35: 897-907.

22. Beug ST, Cheung HH, LaCasse EC, Korneluk RG. Modulation of immune signalling by inhibitors of apoptosis. Trends Immunol 2012; 33: 535-545.

23. Wong WW, Vince JE, Lalaoui N, Lawlor KE, Chau D, Bankovacki A et al. cIAPs and XIAP regulate myelopoiesis through cytokine production in an RIPK1- and RIPK3dependent manner. Blood 2014; 123: 2562-2572.

24. Robinson N, McComb S, Mulligan R, Dudani R, Krishnan L, Sad S. Type I interferon induces necroptosis in macrophages during infection with Salmonella enterica serovar Typhimurium. Nat Immunol 2012; 13: 954-962.

25. Broz P, Newton K, Lamkanfi M, Mariathasan S, Dixit VM, Monack DM. Redundant roles for inflammasome receptors NLRP3 and NLRC4 in host defense against Salmonella. J Exp Med 2010; 207: 1745-1755.

26. Curtsinger JM, Schmidt CS, Mondino A, Lins DC, Kedl RM, Jenkins MK et al. Inflammatory cytokines provide a third signal for activation of naive CD4+ and CD8+ T cells. J Immunol 1999; 162: 3256-3262.

27. Schweitzer AN, Borriello F, Wong RC, Abbas AK, Sharpe AH. Role of costimulators in T cell differentiation: studies using antigen-presenting cells lacking expression of CD80 or CD86. J Immunol 1997; 158: 2713-2722.

28. Keir ME, Butte MJ, Freeman GJ, Sharpe AH. PD-1 and its ligands in tolerance and immunity. Annu Rev Immunol 2008; 26: 677-704.

29. Krummel MF, Allison JP. CD28 and CTLA-4 have opposing effects on the response of T cells to stimulation [see comments]. J Exp Med 1995; 182: 459-465.

30. Lindgren SW, Stojiljkovic I, Heffron F. Macrophage killing is an essential virulence mechanism of Salmonella typhimurium. Proc Natl Acad Sci USA 1996; 93: 4197-4201.

31. van der Velden AW, Velasquez M, Starnbach MN. Salmonella rapidly kill dendritic cells via a caspase-1-dependent mechanism. J Immunol 2003; 171: 6742-6749.

32. Barber DL, Wherry EJ, Masopust D, Zhu B, Allison JP, Sharpe AH et al. Restoring function in exhausted CD8 T cells during chronic viral infection. Nature 2006; 439: 682-687.

33. Sad S, Kagi D, Mosmann TR. Perforin and Fas killing by CD8+ T cells limits their cytokine synthesis and proliferation. J Exp Med 1996; 184: 1543-1547.

34. Dustin ML, Bromley SK, Kan Z, Peterson DA, Unanue ER. Antigen receptor engagement delivers a stop signal to migrating T lymphocytes. Proc Natl Acad Sci USA 1997; 94: 3909-3913.

35. Gunzer M, Weishaupt C, Hillmer A, Basoglu Y, Friedl P, Dittmar KE et al. A spectrum of biophysical interaction modes between $T$ cells and different antigen-presenting cells during priming in 3-D collagen and in vivo. Blood 2004; 104: 2801-2809. 
36. Yrlid U, Wick MJ. Salmonella-induced apoptosis of infected macrophages results in presentation of a bacteria-encoded antigen after uptake by bystander dendritic cells. J Exp Med 2000; 191: 613-624.

37. Winau F, Weber S, Sad S, de Diego J, Hoops SL, Breiden B et al. Apoptotic vesicles crossprime CD8 T cells and protect against tuberculosis. Immunity 2006; 24: 105-117.

38. den Haan JM, Lehar SM, Bevan MJ. CD8(+) but not CD8(-) dendritic cells cross-prime cytotoxic T cells in vivo. J Exp Med 2000; 192: 1685-1696.

39. Houde M, Bertholet S, Gagnon E, Brunet S, Goyette G, Laplante A et al. Phagosomes are competent organelles for antigen cross-presentation. Nature 2003; 425: 402-406.

40. Goldszmid RS, Coppens I, Lev A, Caspar P, Mellman I, Sher A. Host ER-parasitophorous vacuole interaction provides a route of entry for antigen cross-presentation in Toxoplasma gondii-infected dendritic cells. J Exp Med 2009; 206: 399-410.

41. Shen $\mathrm{L}$, Rock KL. Priming of T cells by exogenous antigen cross-presented on MHC class I molecules. Curr Opin Immunol 2006; 18: 85-91.

42. Shutinoski B, Alturki NA, Rijal D, Bertin J, Gough PJ, Schlossmacher MG et al. K45A mutation of RIPK1 results in poor necroptosis and cytokine signaling in macrophages, which impacts inflammatory responses in vivo. Cell Death Differ 2016; 23: 1628-1637.

43. Meylan E, Burns K, Hofmann K, Blancheteau V, Martinon F, Kelliher M et al. RIP1 is an essential mediator of Toll-like receptor 3-induced NF-[kappa]B activation. Nat Immunol 2004; 5: 503-507.

44. Berger SB, Kasparcova V, Hoffman S, Swift B, Dare L, Schaeffer M et al. Cutting Edge: RIP1 kinase activity is dispensable for normal development but is a key regulator of inflammation in SHARPIN-deficient mice. J Immunol 2014; 192: 5476-5480.

45. Yatim N, Jusforgues-Saklani H, Orozco S, Schulz O, Barreira da Silva R, Reis e Sousa C et al. RIPK1 and NF-kappaB signaling in dying cells determines cross-priming of CD8(+) T cells. Science 2015; 350: 328-334.

46. Miao EA, Leaf IA, Treuting PM, Mao DP, Dors M, Sarkar A et al. Caspase-1-induced pyroptosis is an innate immune effector mechanism against intracellular bacteria. Nat Immunol 2010; 11: 1136-1142.

47. Brennan MA, Cookson BT. Salmonella induces macrophage death by caspase-1-dependent necrosis. Mol Microbiol 2000; 38: 31-40.
48. Raupach B, Peuschel SK, Monack DM, Zychlinsky A. Caspase-1-mediated activation of interleukin-1beta (IL-1beta) and IL-18 contributes to innate immune defenses against Salmonella enterica serovar Typhimurium infection. Infect Immun 2006; 74: 4922-4926.

49. van de Veerdonk FL, Netea MG, Dinarello CA, Joosten LA. Inflammasome activation and IL-1beta and IL-18 processing during infection. Trends Immunol 2011; 32 110-116.

50. Vince JE, Wong WW, Gentle I, Lawlor KE, Allam R, O'Reilly L et al. Inhibitor of apoptosis proteins limit RIP3 kinase-dependent interleukin-1 activation. Immunity 2012; 36: 215-227.

51. Philip NH, Dillon CP, Snyder AG, Fitzgerald P, Wynosky-Dolfi MA, Zwack EE et al. Caspase8 mediates caspase-1 processing and innate immune defense in response to bacteria blockade of NF-kappaB and MAPK signaling. Proc Natl Acad Sci USA 2014; 111: 7385-7390.

52. Bossaller L, Chiang PI, Schmidt-Lauber C, Ganesan S, Kaiser WJ, Rathinam VA et al. Cutting edge: FAS (CD95) mediates noncanonical IL-1beta and IL-18 maturation via caspase-8 in an RIP3-independent manner. J Immunol 2012; 189: 5508-5512.

53. Man SM, Tourlomousis P, Hopkins L, Monie TP, Fitzgerald KA, Bryant CE. Salmonella infection induces recruitment of Caspase- 8 to the inflammasome to modulate IL-1beta production. J Immunol 2013; 191: 5239-5246.

54. Kang TB, Yang SH, Toth B, Kovalenko A, Wallach D. Caspase-8 blocks kinase RIPK3-mediated activation of the NLRP3 inflammasome. Immunity 2013; 38: 27-40.

55. Kang S, Fernandes-Alnemri T, Rogers C, Mayes L, Wang Y, Dillon C et al. Caspase-8 scaffolding function and MLKL regulate NLRP3 inflammasome activation downstream of TLR3. Nat Commun 2015; 6: 7515 .

56. Tzelepis F, Alcon V, Dudani R, Gurnani K, Zafer A, Everson ES et al. Modulation of antigenic location converts chronic into acute infection by forcing CD8(+) T cell recognition. Cell Rep 2012; 2: 1710-1721.

57. Patel R, Sad S. Transcription factor Batf3 is important for development of CD8+ T-cell response against a phagosomal bacterium regardless of the location of antigen. Immunol Cell Biol 2016; 94: 378-387.

\section{Supplementary Information accompanies this paper on Death and Differentiation website (http://www.nature.com/cdd)}

